\title{
Iterative Algorithms for a Finite Family of Multivalued Quasi-Nonexpansive Mappings
}

\author{
C. Diop, M. Sene, and N. Djitté \\ Department of Mathematics, Gaston Berger University, P.O. Box 234, Saint Louis, Senegal \\ Correspondence should be addressed to N. Djitté; ngalla.djitte@ugb.edu.sn
}

Received 21 July 2014; Revised 13 October 2014; Accepted 16 October 2014; Published 13 November 2014

Academic Editor: Ting-Zhu Huang

Copyright (C) 2014 C. Diop et al. This is an open access article distributed under the Creative Commons Attribution License, which permits unrestricted use, distribution, and reproduction in any medium, provided the original work is properly cited.

Let $K$ be a nonempty closed and convex subset of a uniformly convex real Banach space $E$ and let $T_{1}, \ldots, T_{m}: K \rightarrow 2^{K}$ be $m$ multivalued quasi-nonexpansive mappings. A new iterative algorithm is constructed and the corresponding sequence $\left\{x_{n}\right\}$ is proved to be an approximating fixed point sequence of each $T_{i}$; that is, $\lim d\left(x_{n} ; T x_{n}\right)=0$. Then, convergence theorems are proved under appropriate additional conditions. Our results extend and improve some important recent results (e.g., Abbas et al. (2011)).

\section{Introduction}

Let $(X, d)$ be a metric space, $K$ a nonempty subset of $X$, and $T: K \rightarrow 2^{K}$ a multivalued mapping. An element $x \in K$ is called a fixed point of $T$ if $x \in T x$. For single valued mapping, this reduces to $T x=x$. The fixed point set of $T$ is denoted by $F(T):=\{x \in K: x T x\}$.

For several years, the study of fixed point theory for multivalued nonlinear mappings has attracted, and continues to attract, the interest of several well known mathematicians (see, e.g., Brouwer [1], Kakutani [2], Nash [3, 4], Geanakoplos [5], Nadler Jr. [6], and Downing and Kirk [7]).

Interest in the study of fixed point theory for multivalued nonlinear mappings stems, perhaps, mainly from its usefulness in real-world applications such as Game Theory and Nonsmooth Differential Equations.

Game Theory. Nash showed the existence of equilibria for noncooperative static games as a direct consequence of multivalued Brouwer or Kakutani fixed point theorem. More precisely, under some regularity conditions, given a game, there always exists a multivalued mapping whose fixed points coincide with the equilibrium points of the game. This, among other things, made Nash a recipient of Nobel Prize in Economic Sciences in 1994. However, it has been remarked that the applications of this theory to equilibrium are mostly static: they enhance understanding conditions under which equilibrium may be achieved but do not indicate how to construct a process starting from a nonequilibrium point and convergent to equilibrium solution. This is part of the problem that is being addressed by iterative methods for fixed point of multivalued mappings.

Nonsmooth Differential Equations. A large number of problems from mechanics and electrical engineering lead to differential inclusions and differential equations with discontinuous right-hand sides, for example, a dry friction force of some electronic devices. Below are two models:

$$
\frac{d u}{d t}=f(t, u), \quad \text { a.e. } t \in I:=[-a, a], u(0)=u_{0},
$$

where $a$ and $u_{0}$ are fixed in $\mathbb{R}$. These types of differential equations do not have solutions in the classical sense. A generalized notion of solution is what is called a solution in the sense of Fillipov.

Consider the following multivalued initial value problem:

$$
\begin{gathered}
-\frac{d^{2} u}{d t^{2}} \in u-\frac{1}{4}-\frac{1}{4} \operatorname{sign}(u-1) \quad \text { on } \Omega=(0, \pi) ; \\
u(0)=0 ; \\
u(\pi)=0 .
\end{gathered}
$$


Under some conditions, the solutions set of (1) and (2) coincides with the fixed point set of some multivalued mappings.

Let $D$ be a nonempty subset of a normed linear space $E$. The set $D$ is called proximinal (see, e.g., [8-10]) if for each $x \in E$, there exists $u \in D$ such that

$$
d(x, u)=\inf \{\|x-y\|: y \in D\}=d(x, D),
$$

where $d(x, y)=\|x-y\|$ for all $x, y \in E$. Every nonempty, closed, and convex subset of a real Hilbert space is proximinal. We denote by $C B(D)$ the families of nonempty closed and bounded subsets of $D, K(D)$ the families of nonempty compact subsets of $D$, and $C(D)$ the families of nonempty compact convex subsets of $D$. The Hausdorffmetric on $C B(K)$ is defined by

$$
H(A, B)=\max \left\{\sup _{a \in A} d(a, B), \sup _{b \in B} d(b, A)\right\}
$$

for all $A, B \in C B(K)$. A multivalued mapping $T: D(T) \subseteq$ $E \rightarrow C B(E)$ is called Lipschitzian if there exists $L>0$ such that

$$
H(T x, T y) \leq L\|x-y\| \quad \forall x, y \in D(T) .
$$

When $L \in(0,1)$ in (5), we say that $T$ is a contraction, and $T$ is called nonexpansive if $L=1$. Finally, A multivalued mapping $T: K \rightarrow C B(K)$ is said to be quasi-nonexpansive if $F(T) \neq \emptyset$ and $H(T x, T p) \leq\|x-p\|$ for all $x \in K$ and $p \in F(T)$.

Several papers deal with the problem of approximating fixed points of multivalued nonexpansive mappings (see, e.g., [8-12] and the references therein) and their generalizations (see, e.g., [13-15]).

On the other hand, Abbas et al. [11] introduced a new one-step iterative process for approximating a common fixed point of two multivalued nonexpansive mappings in a real uniformly convex Banach space and established weak and strong convergence theorems for the proposed process under some basic boundary conditions. Let $S, T: K \rightarrow C B(K)$ be two multivalued nonexpansive mappings. They introduced the following iterative scheme:

$$
\begin{gathered}
x_{1} \in K, \\
x_{n+1}=a_{n} x_{n}+b_{n} y_{n}+c_{n} z_{n},
\end{gathered}
$$

where $y_{n} \in T x_{n}$ and $z_{n} \in S x_{n}$ are such that

$$
\begin{gathered}
\left\|y_{n}-p\right\| \leq d\left(p, S x_{n}\right) \\
\left\|z_{n}-p\right\| \leq d\left(p, T x_{n}\right)
\end{gathered}
$$

and $\left\{a_{n}\right\},\left\{b_{n}\right\}$, and $\left\{c_{n}\right\}$ are real sequences in $(0,1)$ satisfying $a_{n}+b_{n}+c_{n}=1$.

The following lemma is a consequence of the definition of Hausdorff metric, as remarked by Nadler Jr. [6].

Lemma 1. Let $A, B \in C B(X)$ and $a \in A$. For every $\gamma>0$, there exists $b \in B$ such that

$$
d(a, b) \leq H(A, B)+\gamma .
$$

Following the work of Abbas et al. [11], Rashwan and Altwqi [16] introduced a new scheme for approximation of a common fixed point of three multivalued nonexpansive mappings in uniformly convex Banach space. Let $T, S, R: K \rightarrow$ $C B(K)$ be three multivalued nonexpansive mappings. They employed the following iterative process:

$$
\begin{gathered}
x_{1} \in K, \\
x_{n+1}=a_{n} y_{n}+b_{n} z_{n}+c_{n} w_{n}, \quad n \geq 1,
\end{gathered}
$$

where $y_{n} \in T x_{n}, z_{n} \in S x_{n}$, and $w_{n} \in R x_{n}$ are such that

$$
\begin{aligned}
\left\|y_{n}-y_{n+1}\right\| & \leq H\left(T x_{n}, T x_{n+1}\right)+\eta_{n} ; \\
\left\|z_{n}-z_{n+1}\right\| & \leq H\left(S x_{n}, S x_{n+1}\right)+\eta_{n} ; \\
\left\|w_{n}-w_{n+1}\right\| & \leq H\left(R x_{n}, R x_{n+1}\right)+\eta_{n}
\end{aligned}
$$

and $\left\{a_{n}\right\},\left\{b_{n}\right\}$, and $\left\{c_{n}\right\}$ are real sequences in $(0,1)$ satisfying $a_{n}+b_{n}+c_{n}=1$.

Remark 2. Note that if $y_{n}, z_{n}$, and $w_{n}$ are known, then the existence of $y_{n+1}, z_{n+1}$, and $w_{n+1}$ satisfying (10) is guaranteed by Lemma 1.

Before we state the result of Rashwan and Altwqi [16], we need the following definition.

The mappings $T, S, R: K \rightarrow C B(K)$ are said to satisfy condition $(C)$ if $d(x, y) \leq d(z, y)$, for $z \in T x$ and $y \in S x$, or $d(x, y) \leq d(z, y)$, for $z \in T x$ and $y \in R x$, or $d(x, y) \leq d(z, y)$, for $z \in R x$ and $y \in S x$.

Let $F=F(T) \cap F(S) \cap F(R)$ be the set of all common fixed points of the mappings $T, S$, and $R$.

Theorem RA (Rashwan and Altwqi [16]). Let E be a uniformly convex Banach space and $K$ a nonempty closed and convex subset of E. Let T, $S, R: K \rightarrow C B(K)$ be multivalued nonexpansive mappings satisfying condition $(C)$ and $\left\{x_{n}\right\}$ the sequence defined by (9) and (10). If $F \neq \emptyset$ and $T p=S p=R p=\{p\}$ for any $p \in F$, then

$\lim _{n \rightarrow \infty} d\left(x_{n}, T x_{n}\right)=\lim _{n \rightarrow \infty} d\left(x_{n}, S x_{n}\right)=0=\lim _{n \rightarrow \infty} d\left(x_{n}, R x_{n}\right)$.

Recently, Bunyawat and Suantai [17] introduced a onestep iterative scheme for finding a common fixed point of a finite family of multivalued quasi-nonexpansive mappings in a uniformly convex real Banach space. They proposed the following algorithm: let $K$ be a nonempty closed and convex subset of a uniformly convex real Banach space $E$ and $T_{1}, T_{2}, \ldots, T_{m}: K \rightarrow C B(K)$ multivalued quasi-nonexpansive mappings. Let $\left\{x_{n}\right\}$ be the sequence defined iteratively from $x_{1} \in K$ by

$$
x_{n+1}=a_{n, 0} x_{n, 0}+a_{n, 1} x_{n, 1}+\cdots+a_{n, m} x_{n, m}, \quad n \geq 1,
$$

where the sequence $\left\{a_{n, i}\right\} \subset[0,1)$ satisfies $\sum_{i=0}^{m} a_{n, i}=1 \forall n \geq$ 1 and $x_{n, i} \in T_{i} x_{n}$ with $d\left(p, x_{n, i}\right)=d\left(p, T_{i} x_{n}\right)$.

Then, they proved the following theorem.

Theorem BS (Bunyawat and Suantai [17]). Let $E$ be a real Banach space and $K$ a closed convex subset of $X$. 
Let $\{$ Ti: $i=1,2, \ldots, m\}$ be a finite family of multivalued quasinonexpansive mappings from $K$ into $C(K)$ with $F$ := $\cap_{i=1}^{m} F(T i) \neq \emptyset$. Then the sequence $x_{n}$ defined by (12) converges strongly to a common fixed point of $\{T i: i=1,2, \ldots, m\}$ if and only if $\lim \inf d\left(x_{n}, F\right)=0$.

It is our purpose in this paper to construct a new iterative algorithm and prove strong convergence theorems for approximating a common fixed point of a finite family of multivalued quasi-nonexpansive mappings in uniformly convex real Banach spaces. The class of mappings used in our theorems is much more larger than that of multivalued nonexpansive mappings. Our theorems generalize and extend those of Abbas et al. [11], Rashwan and Altwqi [16], and Bunyawat and Suantai [17] and many other important results.

\section{Preliminaries}

Lemma 3 (Chang et al. [18]). Let E be a uniformly convex real Banach space. For arbitrary $r>0$, let $B_{r}(0)=\{x \in E:\|x\| \leq$ $r\}$. Then, for any given subset $\left\{u_{1}, u_{2}, \ldots, u_{N}\right\} \subset B_{r}(0)$ and for any positive real numbers $\lambda_{1}, \lambda_{2}, \ldots, \lambda_{N}$ with $\lambda_{1}+\lambda_{2}+$ $\cdots+\lambda_{N}=1$, there exists a continuous, strictly increasing, and convex function $g:[0,2 r] \rightarrow[0,+\infty)$ with $g(0)=0$ such that, for any $i, j \in\{1,2, \ldots, N\}$ with $i<j$,

$$
\left\|\sum_{k=1}^{N} \lambda_{k} u_{k}\right\|^{2} \leq \sum_{k=1}^{N} \lambda_{k}\left\|u_{k}\right\|^{2}-\lambda_{i} \lambda_{j} g\left(\left\|u_{i}-u_{j}\right\|\right) .
$$

\section{Main Results}

In this paper, we propose the following iterative algorithm.

Let $m \geq 1$ and $K$ a nonempty closed convex subset of a uniformly convex real Banach space $E$. Let $T_{1}, \ldots, T_{m}: K \rightarrow$ $C B(K)$ be multivalued quasi-nonexpansive mappings. Let $\left\{x_{n}\right\}$ be a sequence defined iteratively as follows:

$$
\begin{gathered}
x_{1} \in K, \\
x_{n+1}=\lambda_{0} x_{n}+\lambda_{1} u_{n}^{1}+\cdots+\lambda_{m} u_{n}^{m},
\end{gathered}
$$

where $u_{n}^{i} \in T_{i} x_{n}, i=1, \ldots, m, \lambda_{i} \in(0,1), i=0,1, \ldots, m$, with $\lambda_{0}+\lambda_{1}+\cdots \lambda_{m}=1$. In the sequel, we will write $F:=$ $\cap_{i=1}^{m} F\left(T_{i}\right)$ for the set of common fixed points of the mappings $T_{i}, i=1, \ldots, m$.

Lemma 4. Let $K$ be a nonempty, closed, and convex subset of a real Banach space E. For $m \geq 1$, let $\left\{T_{i}: i=1,2, \ldots, m\right\}$ be a finite family of multivalued quasi-nonexpansive mappings from $K$ into $C B(K)$ with $F:=\bigcap_{i=1}^{m} F\left(T_{i}\right) \neq \emptyset$ and such that $T_{i}(p)=\{p\} \forall p \in F$ and $i=1,2, \ldots, m$. Let $\left\{x_{n}\right\}$ be the sequence defined by (14). Then, for all $p \in F, \lim _{n \rightarrow \infty}\left\|x_{n}-p\right\|$ exits.
Proof. Let $p \in F$. By (14) and the quasi-nonexpansiveness of $T_{i}$ we have

$$
\begin{aligned}
\left\|x_{n+1}-p\right\| & =\left\|\lambda_{0}\left(x_{n}-p\right)+\sum_{i=1}^{m} \lambda_{i}\left(u_{n}^{i}-p\right)\right\| \\
& \leq\left\|\lambda_{0}\left(x_{n}-p\right)\right\|+\sum_{i=1}^{m} \lambda_{i}\left\|u_{n}^{i}-p\right\| \\
& \leq \lambda_{0}\left\|x_{n}-p\right\|+\sum_{i=1}^{m} \lambda_{i} H\left(T_{i} x_{n}, T_{i}(p)\right) \\
& \leq \lambda_{0}\left\|x_{n}-p\right\|+\sum_{i=1}^{m} \lambda_{i}\left\|x_{n}-p\right\|=\left\|x_{n}-p\right\| .
\end{aligned}
$$

Equation (15) implies that the sequence $\left\{\left\|x_{n}-p\right\|\right\}$ is monotonically decreasing. Since it is bounded from below by 0 , we conclude that $\lim _{n \rightarrow \infty}\left\|x_{n}-p\right\|$ exists.

Next, we prove the following theorem.

Theorem 5. Let $K$ be a nonempty, closed, and convex subset of a real uniformly convex Banach space $E$. For $i=1, \ldots, m$ let $T_{i}: K \rightarrow C B(K)$ be a multivalued quasi-nonexpansive mapping. Suppose that $F \neq \emptyset$ and that $T_{i}(p)=\{p\}$ for all $p \in$ $F$. Let $\left\{x_{n}\right\}$ be the sequence defined by (14). Then, for all $i=$ $1, \ldots, m$,

$$
\lim _{n \rightarrow \infty} d\left(x_{n}, T_{i} x_{n}\right)=0
$$

Proof. Using Lemma 4 and the quasi-nonexpansiveness of $T_{i}$, there exists some positive real $r$ such that

$$
\left\|u_{n}^{i}-p\right\| \leq\left\|x_{n}-p\right\| \leq r .
$$

This implies that, for each $i, 1 \leq i \leq m$,

$$
\left\|u_{n}^{i}-x_{n}\right\| \leq 2 r
$$

Next, let $1 \leq i \leq m$; using inequality (17) and Lemma 3, we have

$$
\begin{aligned}
& \left\|x_{n+1}-p\right\|^{2} \\
& =\left\|\lambda_{0}\left(x_{n}-p\right)+\sum_{k=1}^{m} \lambda_{k}\left(u_{n}^{k}-p\right)\right\|^{2} \\
& \quad \leq \lambda_{0}\left\|x_{n}-p\right\|^{2}+\sum_{k=1}^{m} \lambda_{k}\left\|u_{n}^{k}-p\right\|^{2}-\lambda_{0} \lambda_{i} g\left(\left\|u_{n}^{i}-x_{n}\right\|\right) \\
& \quad \leq \lambda_{0}\left\|x_{n}-p\right\|^{2}+\sum_{k=1}^{m} \lambda_{k}\left\|x_{n}-p\right\|^{2}-\lambda_{0} \lambda_{i} g\left(\left\|u_{n}^{i}-x_{n}\right\|\right) \\
& =\left\|x_{n}-p\right\|^{2}-\lambda_{0} \lambda_{i} g\left(\left\|u_{n}^{i}-x_{n}\right\|\right) .
\end{aligned}
$$

Therefore

$$
\lambda_{0} \lambda_{i} g\left(\left\|u_{n}^{i}-x_{n}\right\|\right) \leq\left\|x_{n}-p\right\|^{2}-\left\|x_{n+1}-p\right\|^{2} .
$$


This implies that

$$
\lim _{n \rightarrow \infty} g\left(\left\|u_{n}^{i}-x_{n}\right\|\right)=0 .
$$

It follows that

$$
\lim _{n \rightarrow \infty}\left\|u_{n}^{i}-x_{n}\right\|=0
$$

Since $u_{n}^{i} \in T_{i} x_{n}$, we have

$$
\lim _{n \rightarrow \infty} d\left(x_{n}, T_{i} x_{n}\right)=0 \quad \forall i=1, \ldots, m .
$$

This completes the proof.

We now approximate common fixed points of $\left\{T_{1}, T_{2}\right.$, $\left.\ldots, T_{m}\right\}$ through strong convergence of the sequence $\left\{x_{n}\right\}$ defined by (14). We start with the following definition.

Definition 6. A family $\left\{T_{1}, \ldots, T_{m}: K \rightarrow C B(K)\right\}$ is said to satisfy Condition $\left(I^{*}\right)$, if there exists a strictly increasing function $f:[0, \infty) \rightarrow[0, \infty)$ with $f(0)=0, f(r)>0$ for all $r \in(0, \infty)$ and $i_{0}, 1 \leq i_{0} \leq m$, such that

$$
d\left(x, T_{i_{0}} x\right) \geq f(d(x, F)) \quad \forall x \in K .
$$

Theorem 7. Let $K$ be a nonempty, closed, and convex subset of a uniformly convex real Banach space $E$. For $m \geq 1$, let $T_{1}, T_{2}, \ldots, T_{m}: K \rightarrow C B(K)$ be a multivalued quasinonexpansive mapping. Assume that $\left\{T_{1}, \ldots, T_{m}\right\}$ satisfies condition $\left(I^{*}\right)$. If $F \neq \emptyset$ and $T_{i}(p)=\{p\}$ for all $p \in F$, then the sequence $\left\{x_{n}\right\}$ converges strongly to a common fixed point of $\left\{T_{i}, i=1, \ldots, m\right\}$.

Proof. From Theorem 5, we have $\lim _{n \rightarrow \infty} d\left(x_{n}, T_{i} x_{n}\right)=0$ for all $i=1,2, \ldots, m$. Using the fact that $\left\{T_{1}, \ldots, T_{m}\right\}$ satisfies condition $\left(I^{*}\right)$, it follows that there exists some $i_{0}$ such that $\lim _{n \rightarrow \infty} f\left(d\left(x_{n}, F\left(T_{i_{0}}\right)\right)\right)=0$. Thus there exist a subsequence $\left\{x_{n_{j}}\right\}$ of $\left\{x_{n}\right\}$ and a sequence $\left\{p_{j}\right\} \subset F\left(T_{i_{0}}\right)$ such that

$$
\left\|x_{n_{j}}-p_{j}\right\|<\frac{1}{2^{j}} \quad \forall j \in \mathbb{N} .
$$

By setting $p_{j}$ in place of $p$ and following the same arguments as in the proof of Lemma 4, we obtain from inequality (15) that

$$
\left\|x_{n_{j+1}}-p_{j}\right\| \leq\left\|x_{n_{j}}-p_{j}\right\|<\frac{1}{2^{j}} .
$$

We now show that $\left\{p_{j}\right\}$ is a Cauchy sequence in $K$. Notice that

$$
\begin{aligned}
\left\|p_{j+1}-p_{j}\right\| & \leq\left\|p_{j+1}-x_{n_{j+1}}\right\|+\left\|x_{n_{j+1}}-p_{j}\right\| \\
& <\frac{1}{2^{j+1}}+\frac{1}{2^{j}}<\frac{1}{2^{j-1}} .
\end{aligned}
$$

This shows that $\left\{p_{j}\right\}$ is a Cauchy sequence in $K$ and thus converges strongly to some $p \in K$. Using the fact that $T_{i}$ is quasi-nonexpansive and $p_{j} \rightarrow p$, we have

$$
d\left(p_{j}, T_{i}(p)\right) \leq H\left(T_{i}(p)_{j}, T_{i}(p)\right) \leq\left\|p_{j}-p\right\|,
$$

so that $d\left(p, T_{i}(p)\right)=0$ and thus $p \in T_{i}(p)$. Therefore, $p \in$ $F\left(T_{i}\right)$ and $\left\{x_{n_{j}}\right\}$ converges strongly to $p$. Setting $p_{j}$ in place of $p$ in the proof of Lemma 4 , it follows from inequality (15) that $\lim _{n \rightarrow \infty}\left\|x_{n}-p\right\|$ exists. So, $\left\{x_{n}\right\}$ converges strongly to $p$. This completes the proof.

Definition 8. A mapping $T: K \rightarrow C B(K)$ is called hemicompact if, for any sequence $\left\{x_{n}\right\}$ in $K$ such that $d\left(x_{n}, T x_{n}\right) \rightarrow 0$ as $n \rightarrow \infty$, there exists a subsequence $\left\{x_{n_{j}}\right\}$ of $\left\{x_{n}\right\}$ such that $x_{n_{j}} \rightarrow p \in K$. One notes that if $K$ is compact, then every multivalued mapping $T: K \rightarrow C B(K)$ is hemicompact.

Theorem 9. Let $K$ be a nonempty, closed, and convex subset of a uniformly convex real Banach space $E$. For $i=1, \ldots, m$ let $T_{i}: K \rightarrow C B(K)$ be a multivalued continuous and quasinonexpansive mapping. Assume that $T_{i_{0}}$ is hemicompact for some $i_{0}$. If $F \neq \emptyset$ and $T_{i}(p)=\{p\}$ for all $p \in F$, then the sequence $\left\{x_{n}\right\}$ defined by (14) converges strongly to a common fixed point of $\left\{T_{i}, i=1, \ldots, m\right\}$.

Proof. From Theorem 5, we have that $\lim _{n \rightarrow \infty} d\left(x_{n}, T_{i} x_{n}\right)=$ 0 . Since $T_{i_{0}}$ is hemicompact, there exists a subsequence $\left\{x_{n_{j}}\right\}$ of $\left\{x_{n}\right\}$ such that $x_{n_{j}} \rightarrow p$ for some $p \in K$. Since for each $i=$ $1,2, \ldots, m, T_{i}$ is continuous, we have $d\left(x_{n_{j}}, T_{i} x_{n_{j}}\right) \rightarrow$ $d\left(p, T_{i}(p)\right)$. Therefore, $d\left(p, T_{i}(p)\right)=0$ and so $p \in F\left(T_{i}\right)$ for all $i=1,2, \ldots, m$. Setting $x^{*}=p$ in the proof of Theorem 5 , it follows from inequality (15) that the sequence $\left\{\left\|x_{n}-p\right\|\right\}$ is decreasing and bounded from bellow. Therefore, $\lim _{n \rightarrow \infty}\left\|x_{n}-p\right\|$ exists. So, $\left\{x_{n}\right\}$ converges strongly to $p$. This completes the proof.

The following result gives a necessary and sufficient condition for the strong convergence of the sequence in (14) to a common fixed point of a finite family of multivalued nonexpansive maps $T_{i}, i=1,2, \ldots, m$.

Theorem 10. Let $K$ be a nonempty, closed, and convex subset of a real Banach space E. For $i=1, \ldots$, m let $T_{i}: K \rightarrow C B(K)$ be a multivalued nonexpansive mapping. Assume that $F \neq \emptyset$ and that $T_{i}(p)=\{p\}$ for all $p \in F$. Then the sequence $\left\{x_{n}\right\}$ defined by (14) converges strongly to a common fixed point of $\left\{T_{i}, i=1, \ldots, m\right\}$ if and only if $\lim \inf d\left(x_{n}, F\right)=0$.

Proof. The necessity is obvious. Conversely, suppose that $\liminf d\left(x_{n}, F\right)=0$. Let $p \in F$. By (15), we have $\left\|x_{n+1}-p\right\| \leq\left\|x_{n}-p\right\|$. This gives $d\left(x_{n+1}, F\right) \leq d\left(x_{n}, F\right)$. Hence, $\lim d\left(x_{n}, F\right)$ exists. By hypothesis, $\lim \inf d\left(x_{n}, F\right)=0$ so we must have $\lim d\left(x_{n}, F\right)=0$. Next, we show that $\left\{x_{n}\right\}$ is a Cauchy sequence in $K$. Let $\epsilon>0$ be given and since $\lim d\left(x_{n}, F\right)=0$, there exists $N \geq 0$ such that, for all $n \geq N$, we have

$$
d\left(x_{n}, F\right)<\frac{\epsilon}{4} .
$$

In particular, $\inf \left\{\left\|x_{N}-p\right\|: p \in F\right\}<\epsilon / 4$, so there exists $p \epsilon$ $F$ such that

$$
\left\|x_{N}-p\right\|<\frac{\epsilon}{2} .
$$


Now for $m, n \geq N$, we have

$$
\begin{aligned}
\left\|x_{n+m}-x_{n}\right\| & \leq\left\|x_{n+m}-p\right\|+\left\|x_{n}-p\right\| \leq 2\left\|x_{N}-p\right\| \\
& <2\left(\frac{\epsilon}{2}\right)=\epsilon .
\end{aligned}
$$

Hence, $\left\{x_{n}\right\}$ is a Cauchy sequence in a closed subset $K$ of a Banach space $E$ and therefore, it converges in $K$. Let $\lim x_{n}=$ $x^{*}$. Now, for each $i=1,2,3, \ldots, m$, we have

$$
\begin{aligned}
d\left(x^{*}, T_{i} x^{*}\right) & \leq d\left(x^{*}, x_{n}\right)+d\left(x_{n}, T_{i} x_{n}\right)+H\left(T_{i} x_{n}, T_{i} x^{*}\right) \\
& \leq d\left(p, x_{n}\right)+d\left(x_{n}, T_{i} x_{n}\right)+d\left(x_{n}, p\right) .
\end{aligned}
$$

By letting $n \rightarrow+\infty$, it follows that $d\left(x^{*}, T_{i} x^{*}\right)=0, i=$ $1,2,3, \ldots, m$, which implies that $x^{*} \in T_{i} x^{*}$. Consequently, $x^{*} \in F$.

Corollary 11 (Abbas et al. [11]). Let E be a real Banach space and $D$ a nonempty, closed, and convex subset of E. Let T, S be multivalued nonexpansive mappings of $D$ into $K(D)$ such that $F(T) \cap F(S) \neq \emptyset$. Let $\left\{a_{n}\right\},\left\{b_{n}\right\}$, and $\left\{c_{n}\right\}$ be sequences in $(0,1)$ satisfying $a_{n}+b_{n}+c_{n}=1$. Let $\left\{x_{n}\right\}$ be a sequence defined iteratively by

$$
\begin{gathered}
x_{1} \in D \\
x_{n+1}=a_{n} x_{n}+b_{n} y_{n}+c_{n} z_{n}, \quad n \geq 1,
\end{gathered}
$$

where $y_{n} \in T x_{n}, z_{n} \in S x_{n}$ are such that $\left\|y_{n}-p\right\| \leq$ $d\left(p, S x_{n}\right)$ and $\left\|z_{n}-p\right\| \leq d\left(p, T x_{n}\right)$ whenever $p$ is a fixed point of any one of the mappings $T$ and $S$. Then, $\left\{x_{n}\right\}$ converges strongly to a common fixed point of $F(T) \cap F(S)$ if and only if $\liminf d\left(x_{n}, F\right)=0$.

Corollary 12 (Bunyawat and Suantai [17]). Let $E$ be a real Banach space and $K$ a closed convex subset of $X$. Let $\{T i: i=1,2, \ldots, m\}$ be a finite family of multivalued quasi-nonexpansive mappings from $K$ into $C(K)$ with $F:=$ $\cap_{i=1}^{m} F(T i) \neq \emptyset$. Then the sequence $x_{n}$ defined by (12) converges strongly to a common fixed point of $\{T i: i=1,2, \ldots, m\}$ if and only if $\lim \inf d\left(x_{n}, F\right)=0$.

Remark 13. The recursion formula (14) used in our theorems is easier to use than the recursion formula (6) of Abbas et al., the one of Rashwan and Altwqi (9), and the one of Bunyawat and Suantai (12) in the following sense: in our algorithm, $u_{n}^{i} \epsilon$ $T_{i} x_{n}$ for $i=1, \ldots, m$ and do not have to satisfy the restrictive conditions: (7) in the recursion formula (6), (10) in the recursion formulas (9), and similar restrictive conditions in the recursion formula (12).

\section{Conflict of Interests}

The authors declare that there is no conflict of interests regarding the publication of this paper.

\section{Acknowledgment}

The authors thank the referee for his work and his valuable suggestion that helped to improve the presentation of this paper.

\section{References}

[1] L. E. J. Brouwer, "Über Abbildung von Mannigfaltigkeiten," Mathematische Annalen, vol. 71, no. 4, p. 598, 1912.

[2] S. Kakutani, "A generalization of Brouwer's fixed point theorem," Duke Mathematical Journal, vol. 8, no. 3, pp. 457-459, 1941.

[3] J. Nash, "Non-cooperative games," Annals of Mathematics: Second Series, vol. 54, pp. 286-295, 1951.

[4] J. Nash, "Equilibrium points in $n$-person games," Proceedings of the National Academy of Sciences of the United States of America, vol. 36, pp. 48-49, 1950.

[5] J. Geanakoplos, "Nash and Walras equilibrium via Brouwer," Economic Theory, vol. 21, no. 2-3, pp. 585-603, 2003.

[6] S. B. Nadler Jr., "Multivaled contraction mappings," Pacific Journal of Mathematics, vol. 30, pp. 475-488, 1969.

[7] D. Downing and W. A. Kirk, "Fixed point theorems for setvalued mappings in metric and Banach spaces," Mathematica Japonica, vol. 22, no. 1, pp. 99-112, 1977.

[8] B. Panyanak, "Mann and Ishikawa iterative processes for multivalued mappings in Banach spaces," Computers and Mathematics with Applications, vol. 54, no. 6, pp. 872-877, 2007.

[9] K. P. R. Sastry and G. V. R. Babu, "Convergence of ishikawa iterates for a multi-valued mapping with a fixed point," Czechoslovak Mathematical Journal, vol. 55, no. 4, pp. 817-826, 2005.

[10] Y. Song and H. Wang, "Erratum to "Mann and Ishikawa iterative processes for multivalued mappings in Banach spaces" [Comput. Math. Appl. 54 (2007) 872-877]," Computers \& Mathematics with Applications, vol. 55, no. 12, pp. 2999-3002, 2008.

[11] M. Abbas, S. H. Khan, A. R. Khan, and R. P. Agarwal, "Common fixed points of two multivalued nonexpansive mappings by onestep iterative scheme," Applied Mathematics Letters, vol. 24, no. 2, pp. 97-102, 2011.

[12] S. H. Khan, I. Yildirim, and B. E. Rhoades, "A one-step iterative process for two multivalued nonexpansive mappings in Banach spaces," Computers and Mathematics with Applications, vol. 61, no. 10, pp. 3172-3178, 2011.

[13] J. García-Falset, E. Llorens-Fuster, and T. Suzuki, "Fixed point theory for a class of generalized nonexpansive mappings," Journal of Mathematical Analysis and Applications, vol. 375, no. 1, pp. 185-195, 2011.

[14] C. E. Chidume, C. O. Chidume, N. Djitte, and M. S. Minjibir, "Krasnoselskii-type algorithm for fixed points of multi-valued strictly pseudo-contractive mappings," Fixed Point Theory and Applications, vol. 2013, article 58, 2013.

[15] N. Djitte and M. Sene, "Convergence theorems for fixed points of multivalued mappings in Hilbert spaces," International Journal of Analysis, vol. 2014, Article ID 269786, 7 pages, 2014.

[16] R. A. Rashwan and S. M. Altwqi, "One-step iterative scheme for approximating common fixed points of three multivalued nonexpansive mappings," Bulletin of International Mathematical Virtual Institute, vol. 2, no. 1, pp. 77-86, 2012. 
[17] A. Bunyawat and S. Suantai, "Common fixed points of a finite family of multivalued quasi-nonexpansive mappings in uniformly convex Banach spaces," Iranian Mathematical Society: Bulletin, vol. 39, no. 6, pp. 1125-1135, 2013.

[18] S.-S. Chang, J. K. Kim, and X. R. Wang, "Modified block iterative algorithm for solving convex feasibility problems in Banach spaces," Journal of Inequalities and Applications, vol. 2010, Article ID 869684, 14 pages, 2010. 


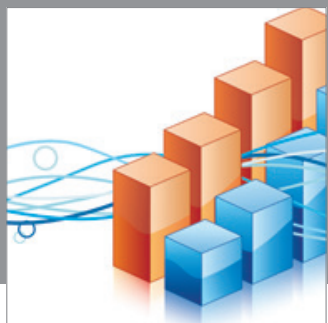

Advances in

Operations Research

mansans

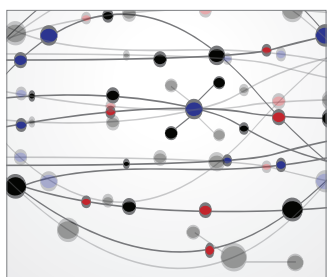

The Scientific World Journal
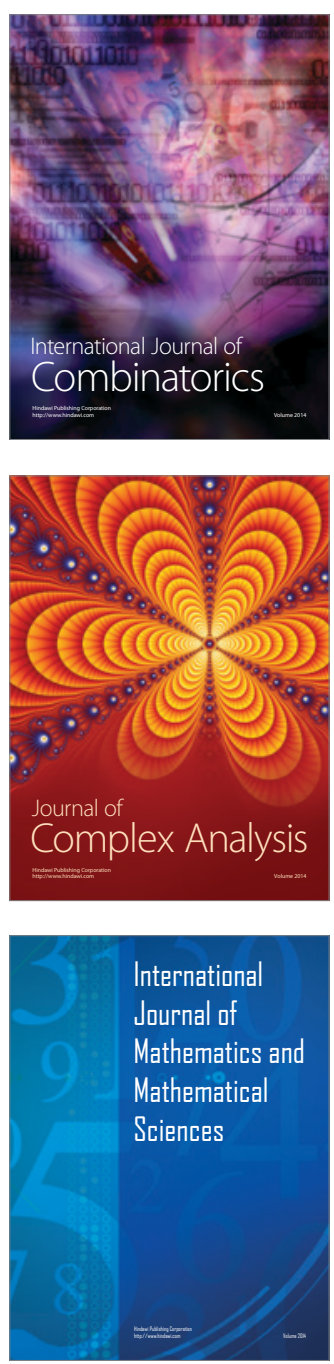
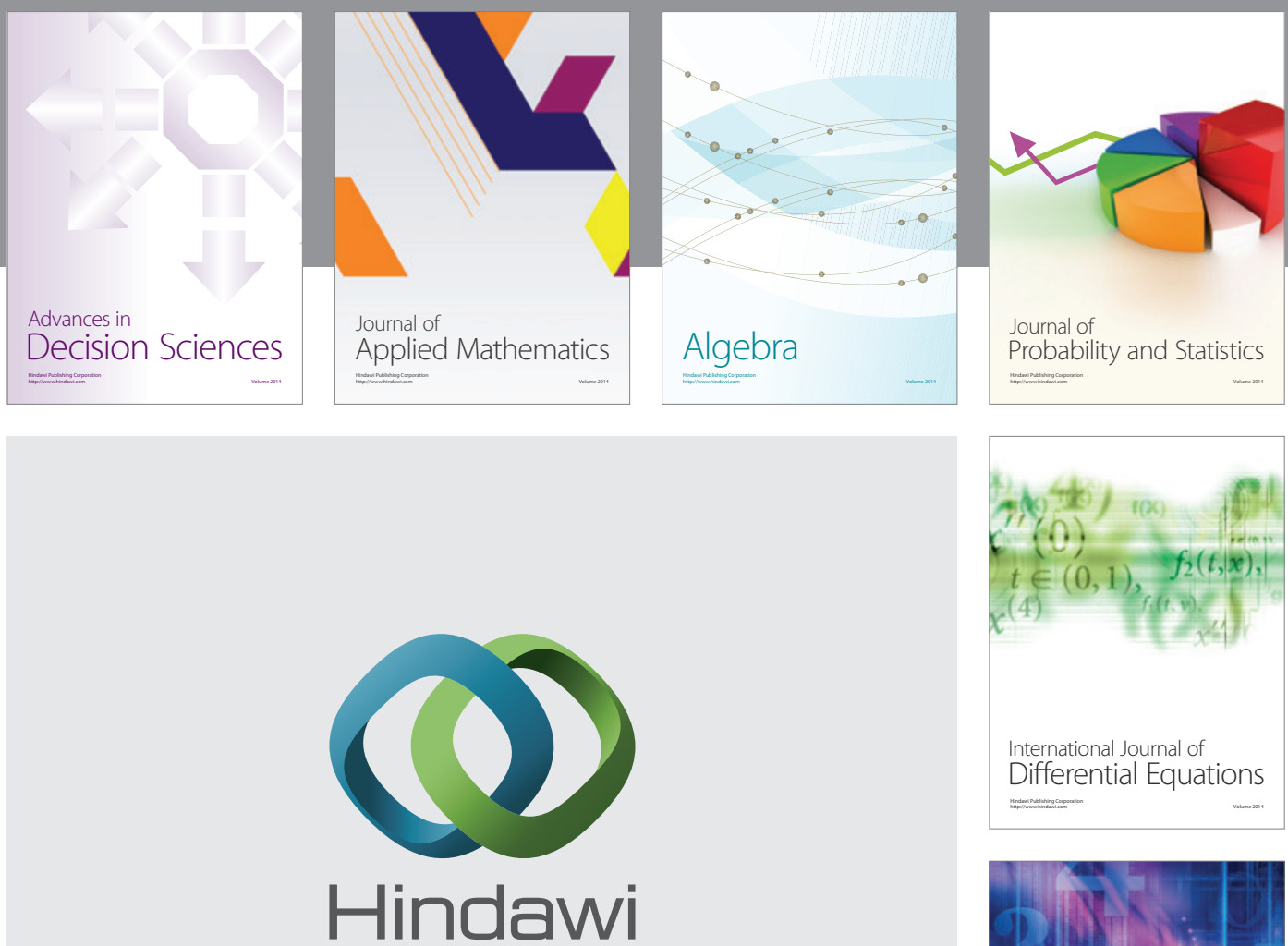

Submit your manuscripts at http://www.hindawi.com
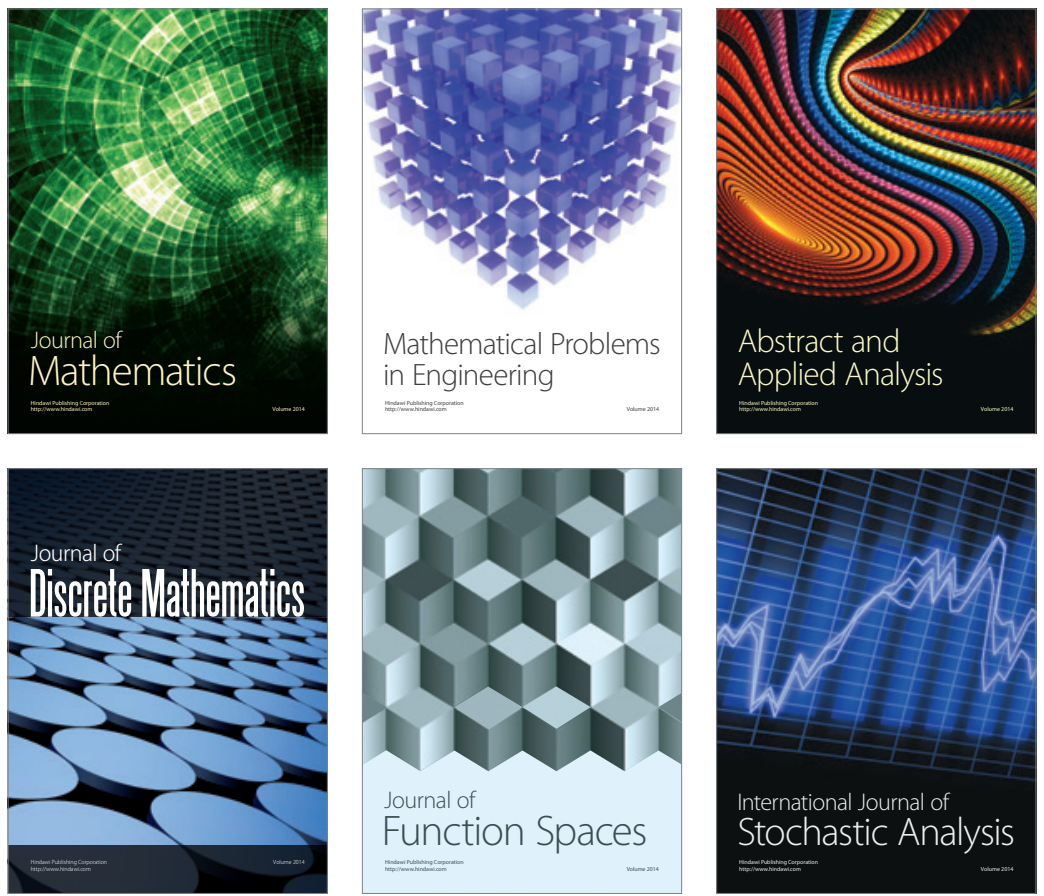

Journal of

Function Spaces

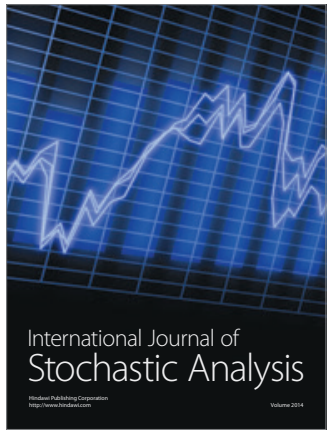

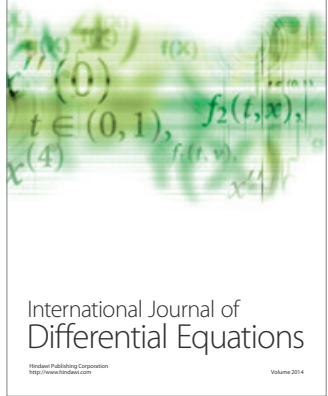
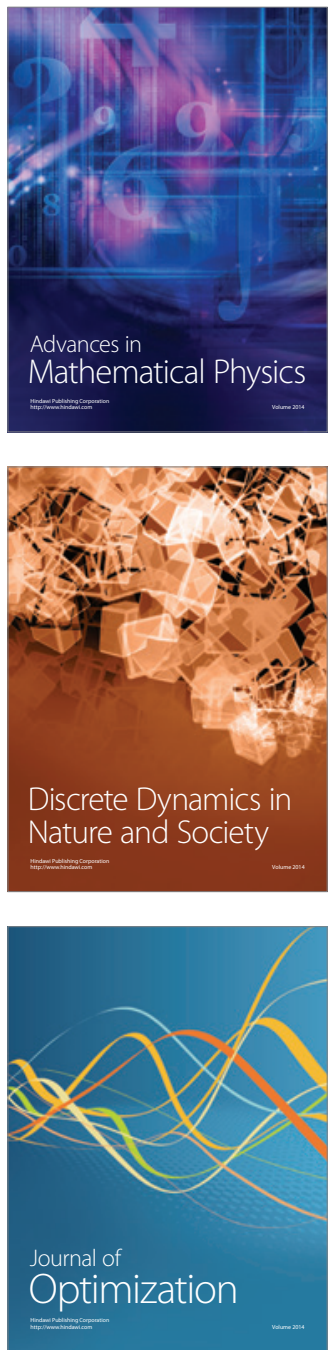